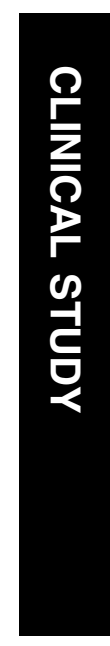

\section{Open-angle glaucoma and systemic thyroid disease in an older population: The Blue Mountains Eye Study}

Department of

Ophthalmology, University

of Sydney, Sydney, Australia

Correspondence: P Mitchell University of Sydney

Department of

Ophthalmology

(Westmead Millennium

Institute Centre for Vision

Research)

Westmead Hospital

Hawkesbury Rd Westmead,

NSW, 2145, Australia

Tel: + 61298457960

Fax: + 61298458345

E-mail: paul_mitchell@

wmi.usyd.edu.au

Received: 6 April 2003

Accepted in revised form: 1 May 2003

Published online: 9 January 2004

This study was supported by the Australian National Health \& Medical Research Council (Grant No. 974159) and the Westmead Millennium Institute, University of Sydney.

This study has been accepted for a paper presentation at ARVO, May 2003.

\begin{abstract}
Purpose To assess whether thyroid disease is independently associated with open-angle glaucoma (OAG), using history of thyroid disease and current thyroxine use.

Methods The Blue Mountains Eye Study examined 3654 persons, aged 49-97 years. Interviewers collected self-reported history of diagnosis and treatment for thyroid disease. Eye examinations included applanation tonometry, stereoscopic optic disc photography and automated perimetry. OAG was diagnosed from the presence of matching typical glaucomatous field changes and optic disc cupping, independent of intraocular pressure. Associations between thyroid disease (history and treatment) and OAG were assessed in a multivariate model.

Results Of 324 participants (8.9\%) reporting history of thyroid disease, $147(4.0 \%)$ were currently using thyroxine. Although we could not accurately categorize the thyroid disorder for all cases, current use of thyroxine suggests a prior hypothyroid state. All thyroid disease subgroups affected women more frequently than men, $P=0.001$. OAG was diagnosed in 108 subjects $(3.0 \%)$ and was more frequent in those reporting past thyroid disease (4.6 $v \mathrm{~s}$ $2.8 \%$ ). This relationship was not statistically significant after adjusting for potential confounders, multivariate odds ratio (OR) 1.6; $95 \%$ confidence interval $(95 \% \mathrm{CI})$ 0.9-2.9. OAG was significantly more frequent, however, in subjects reporting current thyroxine use (6.8 vs $2.8 \%$ ), multivariate OR 2.1; 95\% CI 1.0-4.4, or history of thyroid surgery (6.5 vs $2.8 \%$ ), multivariate OR $2.5 ; 95 \%$ CI 1.0-6.2.
\end{abstract}

AJ Lee, E Rochtchina, JJ Wang, PR Healey and P Mitchell
Conclusions This population-based study suggests that thyroid disease, indicated by current thyroxine use or past thyroid surgery, could be independently related to OAG. Eye (2004) 18, 600-608. doi:10.1038/sj.eye.6700731 Published online 9 January 2004

Keywords: glaucoma; hypothyroidism; population-based; thyroxine; thyroid disease

Introduction

The thyroid gland, under hypothalamicpituitary control, secretes $93 \%$ thyroxine (T4) and 7\% tri-iodothyronine (T3). These hormones increase transcription of several genes, known to affect catabolism. ${ }^{1}$ Iodine deficiency is the most common cause of hypothyroidism worldwide, but in iodine-sufficient regions, autoimmune disease (Hashimoto's thyroiditis) and iatrogenic causes (after thyroid surgery, $\mathrm{I}^{131}$ or antithyroid drug treatment) are more frequent. ${ }^{2,3}$ Hyperthyroidism can be caused by abnormal thyroid stimulation (Graves' disease), intrinsic thyroid autonomy (hyperfunctioning adenoma, toxic multinodular goiter), or excess thyroid stimulating hormone. ${ }^{2}$ Eye involvement in thyroid disease ranges from welldocumented thyroid-associated orbitopathy ${ }^{4}$ to hypothyroid eye changes, including conjunctival and periorbital oedema, blepharoptosis, and nyctalopia. ${ }^{5}$

Although a well-described association exists between open-angle glaucoma (OAG) and thyroid-related orbitopathy, the possible relationship between OAG and either hypothyroidism $^{5-9}$ or hyperthyroidism ${ }^{10}$ 
without orbitopathy is variable as many reports have disputed these findings. ${ }^{4,11-14}$ Current evidence remains confined to case reports ${ }^{8,15}$ or clinic-based studies. ${ }^{4-6,10}$ To our knowledge, no population-based study has assessed the relationship between thyroid disease and OAG.

We aimed therefore to examine whether OAG and history of thyroid disease, including thyroid activity at diagnosis and its treatment, are associated.

\section{Methods}

\section{Study population}

The Blue Mountains Eye Study (BMES) is a populationbased survey of vision and common eye diseases in a representative older Australian community aged 49 years or older, conducted during 1992-1994. The population has been described in several previous reports. ${ }^{16,17}$ In brief, of 4433 eligible residents living in one of two postcode areas in the Blue Mountains region, west of Sydney, Australia, 3654 (82.4\%) participated. After excluding people who died or left the area during the study, the overall response rate was $87.9 \%$. Participants were mostly Caucasian and comparison with the Australian Bureau of Statistics 1991 Census ${ }^{18}$ confirmed an accurate estimation of the target population. The Western Sydney Area Human Ethics Committee approved this project, and written informed consent was obtained from all participants.

\section{Eye examinations}

The methods used to diagnose OAG have been described. ${ }^{17}$ Intraocular pressure (IOP) was measured by Goldmann applanation tonometry. Dilated stereoscopic $30^{\circ}$ colour retinal and optic disc photographs were taken using a Zeiss FF3 fundus camera (Carl Zeiss, Oberkochen, Germany). Optic disc photographs were graded by one of two masked graders using a modified protocol. ${ }^{19}$ For measurement of optic disc dimensions, the camera magnification was corrected using the spherical equivalent refraction of each eye.

Screening automated perimetry (Humphrey 76-point suprathreshold test; Allergan Humphrey, San Leandro, CA, USA) was performed on 3241 subjects (89\%). Of these, $332(9.2 \%)$ were classified as glaucoma suspects because of field defects, ${ }^{17}$ a glaucomatous appearance of the optic disc or a past history of glaucoma or ocular hypertension. These subjects returned for Humphrey 302 full-threshold visual field tests and gonioscopy.

The minimum diagnostic criteria for OAG were an abnormal Humphrey 30-2 Glaucoma Hemifield Test plus one or more of the following field defects not explained by ocular or neurologic causes: (1) arcuate or paracentral scotoma (2) nasal step or (3) advanced glaucomatous field loss. ${ }^{17}$ OAG was diagnosed when typical glaucomatous visual field loss on the Humphrey 30-2 tests matched optic disc rim loss on the stereo photographs, after excluding angle closure, rubeosis, or secondary glaucoma, other than pseudoexfoliation. ${ }^{17}$ Low-pressure glaucoma (LPG) was defined as glaucoma in cases not receiving ocular hypotensive medication, or with previous glaucoma surgery, who had an IOP in both eyes $\leq 21 \mathrm{mmHg}$. Other glaucoma cases were defined as high-pressure glaucoma (HPG). Ocular hypertension $(\mathrm{OH})$ was diagnosed in subjects without characteristic glaucomatous disc or field changes, or secondary glaucoma, but with IOP $\geq 22 \mathrm{mmHg} .{ }^{17}$

A detailed medical and family history was taken, including a history of glaucoma in first-degree relatives. Systemic hypertension was defined as a history of high blood pressure, on current antihypertensive treatment and/or a systolic blood pressure greater than $160 \mathrm{mmHg}$ and/or a diastolic blood pressure greater than $95 \mathrm{mmHg}$. Diabetes was defined as a history of diabetes or fasting venous glucose level $\geq 7.0 \mathrm{mmol} / 1 .{ }^{20}$ Myopia was defined as spherical equivalent refractive error -1.00 dioptre or greater.

\section{Questionnaire}

History of thyroid disease was ascertained including its aetiology, and the age and thyroid activity at diagnosis. Thyroid treatment and its duration were documented. Use of thyroid medication was confirmed in a separate question listing current and past medications. Thyroid status was stratified into three categories according to the reported thyroid activity at diagnosis. Participants with an underacting or overacting thyroid at diagnosis were classified as 'hypothyroid' and 'hyperthyroid', respectively. We classified those subjects with thyroid nodules, adenoma, cysts, goiter, or carcinoma, or in whom we could not determine the thyroid activity at diagnosis as 'unspecified'. Thyroid subjects were also stratified according to the treatment ever received. There were four treatment types: thyroxine (current or past), past $\mathrm{I}^{131}$ treatment, past thyroid surgery, and antithyroid medication use (propylthiouracil or carbimazole). For age-and sex-adjusted and multivariate-analyses, we included subjects with no thyroid disease $(n=3330)$ as the reference group and the thyroid subgroup under analysis.

\section{Data analysis}

All statistical analyses, including $\chi^{2}$ statistic, MantelHaenszel $\chi^{2}$ test, and logistic regression analyses were performed using Statistical Analysis System (SAS, 
version 6.12, SAS Institute, Cary, NC, USA). In multiple logistic regression models, potential confounders included were age (continuously), gender, family history of glaucoma, diabetes, hypertension, myopia, and pseudoexfoliation. Odds ratios (OR) and 95\% confidence intervals $(\mathrm{CI})$ are presented. $P$-values $<0.05$ were considered statistically significant.

\section{Results}

Prevalence and characteristics of thyroid disease

Of the 3654 subjects examined, 324 (8. 9\%) gave a past history of thyroid disease, including hypothyroidism reported by 146 persons (4.0\%) and hyperthyroidism by 73 persons $(2.0 \%)$. The thyroid activity at diagnosis could not be reliably determined in $105(2.9 \%)$ subjects, whose thyroid disease was termed 'unspecified', as shown in Table 1. Of this group of 'unspecified' cases, various thyroid pathologies (nodules, cysts, adenoma, carcinoma, or goiter) were documented in 41 subjects $(12.6 \%$ of all thyroid cases). After stratifying by treatment, 201 (5.5\%) subjects had taken thyroxine at some stage, with 147 persons $(4.0 \%)$ currently using thyroxine. There were 32 participants $(0.9 \%)$ who had received past $\mathrm{I}^{131}$ treatment,

Table 1 Thyroid activity at diagnosis according to treatment ever received, among Blue Mountains Eye Study participants $(n=3654)$

\begin{tabular}{llr}
\hline $\begin{array}{l}\text { Thyroid activity } \\
\text { at diagnosis }\end{array}$ & Treatment received & No. (\%) \\
\hline $\begin{array}{l}\text { Hypothyroid } \\
n=146(4.0 \%)\end{array}$ & Thyroxine & $138(3.8)$ \\
& Surgery and thyroxine & $4(0.1)$ \\
& Unspecified or no treatment & $4(0.1)$ \\
& & \\
Hyperthyroid & $\mathrm{I}^{131}$ only & $17(0.5)$ \\
$n=73(2.0 \%)$ & $\mathrm{I}^{131}$ and thyroxine & $12(0.3)$ \\
& $\mathrm{I}^{131}$, surgery and thyroxine & $3(0.08)$ \\
& Surgery only & $10(0.3)$ \\
& Surgery and thyroxine & $9(0.2)$ \\
& Propylthiouracil or carbimazole & $10(0.3)$ \\
& only & $12(0.3)$ \\
& Unspecified or no treatment & \\
& & $32(0.9)$ \\
Unspecified & Surgery only ${ }^{\mathrm{a}}$ & $34(0.9)$ \\
$n=105(2.9 \%)$ & Surgery and thyroxine & $13(0.4)$ \\
& Iodine tablets only & $26(0.7)$ \\
& Unspecified or no treatment ${ }^{\mathrm{b}, \mathrm{c}}$ & \\
All & & $324(8.9)$ \\
\hline
\end{tabular}

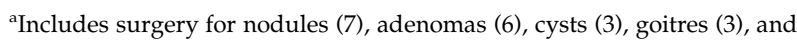
unspecified causes (13).

'Includes surgery for nodules (5), adenoma (1), cyst (1), goitres (2), carcinoma (3), and unspecified causes (22).

Includes unspecified treatment for nodule (1), goitres (8), and unspecified thyroid problems (17).
$92(2.5 \%)$ who gave a history of past thyroid surgery, and $10(0.3 \%)$ persons were currently using antithyroid medications; two participants had active thyroid orbitopathy at the time of the examination.

The prevalence of reported thyroid activity at diagnosis by age and gender is shown in Table 2 . The prevalence of thyroid disease, past or current thyroxine use, past $I^{131}$ treatment or past thyroid surgery were all significantly higher in women than men $(P=0.001)$. Among women, hypothyroidism $(6.7 \%)$ was more common than hyperthyroidism (2.8\%), with the reverse true for men ( $0.5 \%$ hypothyroid, $1.0 \%$ hyperthyroid). There was no significant age-related increase in the prevalence of reported thyroid disease, current thyroxine use and past $\mathrm{I}^{131}$ treatment or past thyroid surgery. The mean age at diagnosis of hypothyroidism, hyperthyroidism, and 'unspecified' thyroid disease was 46.9, 41.1, and 37.6 years, respectively. Current users of thyroxine had an older mean age (68.1 years) than participants without a history of thyroid disease (66.0 years), $P=0.006$. The mean duration of thyroxine use was shorter for past users ( $8 \pm 11.3$ years) compared with current users (14.9 \pm 13.3 years). Although only $14 / 201$ subjects $(7.0 \%)$ who had ever used thyroxine had documented cysts, nodules, adenomas, or goiters prior to thyroid treatment, none of the 10 subjects with glaucoma was receiving thyroxine treatment for thyroid suppression.

\section{Prevalence and characteristics of glaucoma and ocular hypertension}

OAG was diagnosed in 108 persons $(3.0 \%, 95 \%$ CI $2.5-3.6 \%)$, including 54 previously undiagnosed $(50 \%)$ and $36(33.3 \%)$ with LPG. Gender-adjusted logistic regression analysis showed an exponential increase in OAG prevalence with increasing age (per decade). OAG was significantly more frequent in women than men in each 10-year age group (age-adjusted OR 1.55, 95\% CI 1.0-2.3). ${ }^{17} \mathrm{OH}$ was found in 135 persons $(3.7 \%, 95 \% \mathrm{CI}$ $3.1-4.3 \%)$. There was no age-related increase in the prevalence of $\mathrm{OH}$, nor any gender difference.

\section{Thyroid disease associations with glaucoma and ocular hypertension}

Table 3 shows that of the 324 participants who reported a history of any thyroid disease, 15 (4.6\%) had glaucoma. Of these cases, six reported having been hypothyroid and four reported hyperthyroidism. The remaining five cases were 'unspecified'. Among those with glaucoma, LPG $(9 / 15 ; 60 \%)$ was more frequent than HPG $(6 / 15 ; 40 \%)$, $P=0.018$. The association found between thyroid disease and glaucoma was not statistically significant, after adjusting for other independent glaucoma risk factors 
Table 2 Prevalence of thyroid activity at diagosis and type of treatment by gender and age in Blue Mountains Eye Study participants $(n=3654)$

\begin{tabular}{|c|c|c|c|c|c|c|c|c|}
\hline \multirow[t]{3}{*}{ Age Group (years) } & \multirow[t]{3}{*}{ No. } & \multicolumn{3}{|c|}{ Thyroid activity at diagnosis $\%$} & \multicolumn{4}{|c|}{ Treatment $^{\mathrm{a}} \%$} \\
\hline & & \multirow[t]{2}{*}{ Hypothyroid } & \multirow[t]{2}{*}{ Hyperthyroid } & \multirow[t]{2}{*}{ Unspecified } & \multicolumn{2}{|c|}{ Thyroxine } & \multirow{2}{*}{$I^{131}$} & \multirow[t]{2}{*}{ Surgery } \\
\hline & & & & & Current & Past & & \\
\hline \multicolumn{9}{|l|}{ Women } \\
\hline$<60$ & 575 & 4.0 & 3.0 & 3.8 & 3.3 & 2.4 & 1.7 & 2.6 \\
\hline $60-69$ & 720 & 8.3 & 2.2 & 3.8 & 7.2 & 2.9 & 0.8 & 4.2 \\
\hline 70-79 & 557 & 7.2 & 3.1 & 6.1 & 8.3 & 2.3 & 0.9 & 5.2 \\
\hline$\geq 80$ & 220 & 6.8 & 3.6 & 2.7 & 6.4 & 2.3 & 1.4 & 2.7 \\
\hline Total & 2072 & 6.7 & 2.8 & 4.3 & 6.3 & 2.6 & 1.2 & 3.9 \\
\hline \multicolumn{9}{|l|}{ Men } \\
\hline$<60$ & 444 & 0.5 & 0.2 & 0.7 & 0.5 & 0 & 0.2 & 0.5 \\
\hline $60-69$ & 589 & 1.0 & 1.4 & 1.7 & 2.0 & 0.2 & 0.9 & 1.2 \\
\hline 70-79 & 403 & 0 & 1.5 & 0.7 & 0.5 & 0 & 0.5 & 0.7 \\
\hline$\geq 80$ & 146 & 0 & 0 & 0 & 0 & 0 & 0 & 0 \\
\hline Total & 1582 & 0.5 & 1.0 & 1.0 & 1.0 & 0.6 & 0.5 & 0.8 \\
\hline All & 3654 & 4.0 & 2.0 & 2.9 & 4.0 & 1.5 & 0.9 & 2.5 \\
\hline
\end{tabular}

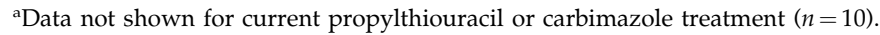

Table 3 Adjusted odds ratios (age-, sex-, and multivariate-) for associations between thyroid activity at diagnosis/treatment for thyroid disease ${ }^{\mathrm{a}}$ and glaucoma

\begin{tabular}{|c|c|c|c|c|}
\hline & \multicolumn{4}{|c|}{ Adjusted odds ratios (95\% confidence intervals) } \\
\hline & \multicolumn{4}{|c|}{ Open-angle glaucoma } \\
\hline & Number at risk & $\%$ affected & Age- and sex-adjusted & Multivariate-adjusted ${ }^{\mathrm{b}}$ \\
\hline \multicolumn{5}{|l|}{ Thyroid activity at diagnosis } \\
\hline No past thyroid disease & 3330 & 2.8 & 1.0 (reference) & 1.0 (reference) \\
\hline Hypothyroid & 146 & 4.1 & $1.3(0.5-3.0)$ & $1.2(0.5-2.9)$ \\
\hline Hyperthyroid & 73 & 5.5 & $2.0(0.7-5.7)$ & $2.1(0.7-6.2)$ \\
\hline Unspecified & 105 & 4.8 & $1.7(0.7-4.5)$ & $1.9(0.9-4.9)$ \\
\hline All & 324 & 4.6 & $1.6(0.9-2.8)$ & $1.6(0.9-2.9)$ \\
\hline \multicolumn{5}{|l|}{ Treatment } \\
\hline No past thyroid disease & 3330 & 2.8 & 1.0 (reference) & 1.0 (reference) \\
\hline \multicolumn{5}{|l|}{ Thyroxine } \\
\hline Ever & 201 & 5.5 & $1.8(0.9-3.5)$ & $1.7(0.9-3.5)$ \\
\hline Past & 54 & 1.9 & $0.6(0.1-4.3)$ & $0.6(0.1-4.7)$ \\
\hline Current & 147 & 6.8 & $2.3(1.1-4.6)$ & $2.1(1.0-4.4)$ \\
\hline $\mathrm{I}^{131}$ (ever) & 32 & 6.3 & $2.6(0.6-11.7)$ & $3.5(0.8-15.7)$ \\
\hline Thyroid surgery (ever) & 92 & 6.5 & $2.6(1.1-6.2)$ & $2.5(1.0-6.2)$ \\
\hline
\end{tabular}

a Results not shown for propylthiouracil or carbimazole treatment.

${ }^{\mathrm{b}}$ Adjusted for age, sex, family history of glaucoma, myopia, diabetes, hypertension, and pseudoexfoliation.

identified in our study participants (multivariate OR 1.6; 95\% CI 0.9-2.9).

Table 3 also shows that the prevalence of glaucoma was significantly higher $(6.8 \%)$ among persons reporting current use of thyroxine than among nonusers (2.8\%). This association remained significant after adjusting for age and sex (OR 2.3; 95\% CI 1.1-4.6), and after adjusting for multiple risk factors (OR 2.1; 95\% CI 1.0-4.4).

Glaucoma prevalence in 10-year age categories among persons currently treated with thyroxine $(n=147)$ and those with no thyroid disease history is shown in Figure 1. For all subjects aged 70 years or older, the 
glaucoma prevalence was more than doubled for those currently using thyroxine. Of the 10 OAG cases currently treated with thyroxine, five reported hypothyroidism, two reported hyperthyroidism, and in three the thyroid disease was unspecified. Nine of the 10 were women, half had newly diagnosed OAG and four had LPG. Thyroxine therapy had been commenced prior to diagnosis of glaucoma in six of the 10 current thyroxine users. Owing to the small numbers, we were unable to determine if the relationship with current thyroxine use was dose-dependent.

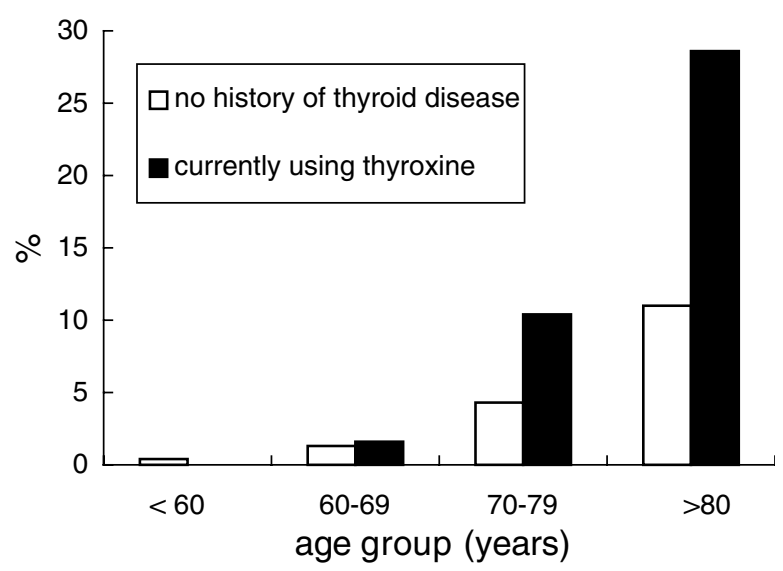

Figure 1 Prevalence of glaucoma by age in participants with no history of thyroid disease $(n=3330)$, compared with those currently using thyroxine $(n=147)$.
There was a similar increase in glaucoma prevalence among subjects who gave a history of past thyroid surgery (6.5\%), multivariate OR 2.5; 95\% CI 1.0-6.2. Of these six subjects, two had a past history of surgery for hyperthyroidism and in four, the type of thyroid disease was unspecified. Thyroxine was later commenced in five subjects. Of the surgical cases, the mean age at which thyroid disease was diagnosed was 41 years in subjects without OAG and 54 years in those with OAG. Of the 32 participants reporting past $\mathrm{I}^{131}$ therapy, two (6.3\%) had OAG. A nonsignificant increased likelihood for OAG in this group was found in multivariate-adjusted analysis (OR 3.5; 95\% CI 0.8-15.7). Current use of antithyroid medication (propylthiouracil or carbimazole) was not associated with glaucoma.

The small numbers did not permit stratification of the glaucoma cases into LPG and HPG for the thyroid treatment subgroups. However, when all the subgroups $(n=324)$ were amalgamated, a statistically significant association was found between thyroid disease and LPG in both age-, sex-, and multivariate-adjusted analyses, OR 3.1 (95\% CI 1.4-7.0).

Table 4 demonstrates no association between thyroid disease or any thyroid treatment subgroup and ocular hypertension. The mean intraocular pressure in persons being treated with thyroxine or subjects with any past thyroid history, was not significantly different from subjects with no thyroid disease history.

Table 5 presents the multivariate model for associations between glaucoma and multiple systemic and ocular risk

Table 4 Adjusted odds ratios (age-, sex-, and multivariate-) for associations between thyroid activity at diagnosis/treatment for thyroid disease ${ }^{\mathrm{a}}$ and ocular hypertension

\begin{tabular}{|c|c|c|c|c|}
\hline & \multicolumn{4}{|c|}{ Adjusted odds ratios (95\% confidence intervals) } \\
\hline & \multicolumn{4}{|c|}{ Ocular hypertension } \\
\hline & Number at risk & $\%$ affected & Age- and sex-adjusted & Multivariate-adjusted $^{\mathrm{b}}$ \\
\hline \multicolumn{5}{|l|}{ Thyroid activity at diagnosis } \\
\hline No past thyroid disease & 3237 & 5.3 & 1.0 (reference) & 1.0 (reference) \\
\hline Hypothyroid & 140 & 4.8 & $0.9(0.4-2.0)$ & $0.9(0.4-2.0)$ \\
\hline Hyperthyroid & 69 & 2.7 & $0.5(0.1-2.2)$ & $0.6(0.1-2.4)$ \\
\hline Unspecified & 100 & 3.8 & $0.7(0.3-2.0)$ & $0.7(0.3-2.0)$ \\
\hline All & 309 & 4.0 & $0.8(0.4-1.4)$ & $0.8(0.4-1.4)$ \\
\hline \multicolumn{5}{|l|}{ Treatment } \\
\hline No past thyroid disease & 3237 & 5.3 & 1.0 (reference) & 1.0 (reference) \\
\hline \multicolumn{5}{|l|}{ Thyroxine } \\
\hline ever & 190 & 4.9 & $1.0(0.5-1.9)$ & $1.0(0.5-1.9)$ \\
\hline past & 53 & 3.7 & $0.7(0.2-2.8)$ & $0.7(0.2-3.0)$ \\
\hline current & 137 & 5.4 & $1.1(0.5-2.2)$ & $1.1(0.5-2.2)$ \\
\hline $\mathrm{I}^{131}$ (ever) & 30 & 6.6 & $1.3(0.3-5.6)$ & $1.6(0.4-6.9)$ \\
\hline Surgery (ever) & 86 & 3.5 & $0.6(0.2-2.0)$ & $0.5(0.2-1.9)$ \\
\hline
\end{tabular}

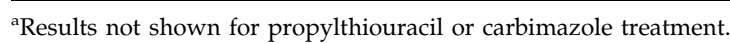

${ }^{\mathrm{b}}$ Adjusted for age, sex, family history of glaucoma, myopia, diabetes, hypertension, and pseudoexfoliation. 
Table 5 Multivariate model of associations between current thyroxine treatment and glaucoma, in participants attending the Blue Mountains Eye Study $(n=3477)^{\text {a }}$

\begin{tabular}{lcccc}
\hline Variable & $\begin{array}{c}\text { Number of } \\
\text { subjects }\end{array}$ & $\begin{array}{c}\text { Condition } \\
\text { prevalence (\%) }\end{array}$ & $\begin{array}{c}\text { Glaucoma } \\
\text { prevalence (\%) }\end{array}$ & $\begin{array}{c}\text { Odds ratio } \\
\text { (95\% confidence interval) }\end{array}$ \\
\hline Age & & & & $1.1(1.08-1.13)$ \\
Sex (female) & 1918 & 55.2 & 3.6 & $1.4(0.8-2.0)$ \\
Family history of glaucoma & 298 & 8.6 & 5.4 & $2.8(1.6-5.1)$ \\
Myopia & 575 & 16.5 & 6.3 & $2.7(1.7-4.2)$ \\
Diabetes & 270 & 7.8 & 5.2 & $1.9(1.1-3.6)$ \\
Hypertension & 1581 & 45.5 & 4.3 & $1.7(1.1-2.6)$ \\
Pseudoexfoliation & 77 & 2.2 & 6.3 & $3.4(1.7-7.1)$ \\
Current thyroxine treatment & 147 & 4.2 & & $2.1(1.0-4.4)$ \\
\hline
\end{tabular}

${ }^{a}$ Includes subjects without thyroid disease $(n=3330)$ and current thyroxine users $(n=147)$.

factors found associated with glaucoma in our study (age, female sex, glaucoma family history, myopia, diabetes, hypertension, presence of pseudoexfoliation, plus current thyroxine treatment). After simultaneous adjustment for these potentially confounding variables, current thyroxine treatment was independently associated with glaucoma, OR 2.13 (95\% CI 1.02-4.42).

\section{Discussion}

To our knowledge, this is the first population-based study to examine the relationship between thyroid disease and glaucoma. The findings suggest that thyroid disease could be an independent risk factor for OAG. After adjusting for other glaucoma risk factors, either current treatment with thyroxine or a history of thyroid surgery was associated with higher glaucoma prevalence.

The prevalence of self-reported thyroid disease in our study was $8.9 \%$, including hypothyroidism in $4.0 \%$ of participants (6.7\% of women and $0.5 \%$ of men) and hyperthyroidism in $2.0 \%$ (2.8\% of women and $1.0 \%$ of men). Our prevalence findings were based on history alone and so cannot be compared closely with studies using serum TSH levels to define thyroid status.

Prevalence rates for thyroid disease will also vary depending on locality (goitrous or non-goitrous regions), selection of participants (hospital clinic vs populationbased), use of diagnostic tests and the particular TSH criterion chosen to define presence of thyroid disease.

The Framingham Study ${ }^{21}$ found that $4.4 \%$ of subjects aged 60 years or older (5.9\% of women and $2.3 \%$ of men) had hypothyroidism defined using serum TSH $>10 \mathrm{mU} /$ 1 , and $5.9 \%$ (7.7\% of women and $3.3 \%$ of men) defined using TSH 5-10 mU/1. A later Framingham report ${ }^{22}$ that included definite, probable or unsuspected hypothyroidism, found hypothyroidism in $8.5 \%(11.7 \%$ of women and $3.9 \%$ of men). The Birmingham Thyrotropin Study ${ }^{23}$ identified hypothyroidism in $11.6 \%$ of women and $2.9 \%$ of men of similar age, defined using serum TSH $>5 \mathrm{mU} / 1$. Our self-reported hypothyroidism prevalence is somewhat lower than in these surveys. Under-ascertainment of thyroid disease in our population could be anticipated. Studies utilizing serum TSH levels will not only detect known cases but also undiagnosed thyroid cases. ${ }^{24,25}$ It is also likely that more accurate determination of thyroid activity of our 'unspecified' participants would have increased our prevalence of both hyperthyroidism and hypothyroidism.

Hyperthyroidism prevalence studies have also been conducted in elderly populations, but perhaps due to less reliable TSH tests for lower values, have been more variable. Prevalence rates ranged from $0.9 \%$ of women and $1.2 \%$ of men in one study defining hyperthyroidism using TSH $<0.2 \mathrm{U} / \mathrm{1}^{26}$ to a second study, which found hyperthyroidism in $6.3 \%$ of women and $5.5 \%$ of men, using TSH $<0.5 \mathrm{mU} / 1 .^{23} \mathrm{~A}$ recent report from Colorado, ${ }^{25}$ however, reported TSH levels $\leq 0.01 \mathrm{mU} / 1$ in $2.2 \%$, similar to our self-reported prevalence.

There are several important limitations to our study. About one-third of patients (32.4\%) who reported past diagnosis of thyroid disease could not provide accurate information about its activity at diagnosis, and this could not be retrieved from their medical records as many diagnoses were made decades earlier. The spectrum of thyroid activity known to occur with other thyroid conditions such as nodules, cysts, adenoma, carcinoma, or goitre prevented any further categorization. ${ }^{3}$ Similarly, we could not always correlate the type of thyroid surgery performed with thyroid activity at diagnosis.

Furthermore, although thyroid eye disease was present in two subjects at the time of examination, we could not ascertain those with past thyroid eye disease.

Lack of biochemical quantification of current thyroid state is an important limitation of our study. Sensitive $\mathrm{TSH}$ assays are regarded as the most accurate means of detecting thyroid disease. However, problems with 
interpretation of elevated or reduced serum TSH levels are recognized. ${ }^{21,23}$ Despite this, our prevalence of current thyroxine use $(4.0 \%)$ is similar to other studies. A UK general practice study ${ }^{23}$ with similar age, gender distribution, ethnicity, and participation to our study, identified $3.6 \%$ of subjects currently using thyroxine. The Colorado Thyroid Disease Prevalence Study ${ }^{25}$ documented $5.9 \%$ of participants reporting thyroid medication use. Thyroid hormone use in the Framingham Study ${ }^{22}$ was higher at 6.9\% (10.0\% women, $2.3 \%$ men), but was documented to be inappropriately used by $12 \%$ of women and $29 \%$ of men.

Thyroxine, as levothyroxine sodium, is indicated for treatment of hypothyroidism and as a suppressive regimen in patients with thyroid cancer and diffuse or nodular goitre. ${ }^{3,27,28}$ All 10 participants with glaucoma currently using thyroxine were being treated for hypothyroidism. A period of hypothyroid function is thus better represented in our study by current thyroxine treatment, rather than reported past history of hypothyroidism as the latter does not include participants with iatrogenic hypothyroidism.

Strengths of our study include its high participation rate, accurate diagnosis of OAG and OHT and detailed documentation of and adjustment for well-known glaucoma risk factors also found associated with OAG in our population. A borderline association between current treatment with thyroxine (suggesting a prior hypothyroid state) and OAG was identified.

Previous case-control studies, using measured TSH levels, have documented conflicting prevalence rates for hypothyroidism, ranging from $4.7 \%$ in controls and $23.9 \%$ in glaucoma cases $(P<0.004),{ }^{5}$ to $4 \%$ in controls and $2.7 \%$ in cases. ${ }^{14}$ Another study that excluded persons currently treated with thyroxine, ${ }^{11}$ reported that $4 \%$ of 100 glaucoma cases had hypothyroidism, which was not significantly different to the population prevalence of hypothyroidism. $^{23}$

A number of studies assessing the prevalence of glaucoma in hypothyroid patients, have generally provided negative findings. ${ }^{9,12,13}$ However, reduced outflow facility was reported in hypothyroid subjects in one small study, ${ }^{9}$ while no such differences were observed in a cross-sectional study of glaucoma prevalence in 100 hypothyroid patients. ${ }^{13}$ No significant IOP differences were found between hypothyroid and hyperthyroid cases in another population, ${ }^{12}$ and the two glaucoma cases identified were in thyrotoxic subjects. We found no association between either between IOP level or $\mathrm{OH}$ and current thyroxine treatment.

The association between current thyroxine use and OAG could be interpreted in at least two ways: (1) Current thyroxine use could be regarded as a surrogate for hypothyroidism. Reduced T3 and T4 levels prior to or during treatment could lead to various effects including increased mucopolysaccharide production, altered myocilin gene regulation, or possibly morphogenetic effects on the optic nerve or (2) thyroxine treatment could have direct toxic effects on ocular structures.

Mucopolysaccharides, including hyaluronic acid, are known to accumulate in the ground substance of the dermis and other tissues in hypothyroidism. ${ }^{29}$ Hyaluronic acid coats the trabecular meshwork and, in excess, has surfactant-like actions, sticking adjacent endothelial membranes together and contributing to aqueous outflow resistance, with resulting IOP elevation and glaucoma. ${ }^{30}$ Recently, thyroid receptor isoforms have been identified on human trabecular meshwork cells, ${ }^{29}$ and $\mathrm{T} 3$, the major active form of thyroxine, has been shown to reduce hyaluronic acid concentration in cell media by around one-third. ${ }^{29}$ Although the mechanisms of the T3 effects on hyaluronic acid metabolism in human trabecular meshwork are unclear, these findings suggest that modulation of hyaluronic acid production in the trabecular meshwork by T3 may help to determine outflow resistance. Identification of mutations of myocilin/trabecular meshwork inducible glucocorticoid response (TIGR) gene in subsets of patients with $\mathrm{OAG}^{31,32}$ has led to intense research regarding functions of this gene. Hypothesized roles of myocilin include increased resistance of aqueous outflow through the trabecular meshwork with subsequent IOP elevation ${ }^{31,33}$ and effects on optic nerve myelination ${ }^{34}$ thus glaucomatous damage. Stress, mechanical perturbations, and steroid treatment induces myocilin expression, ${ }^{33,35,36}$ but endogenous protective regulators, such as basic fibroblast growth factor (bFGF) and T3 but not thyroxine (T4), have recently been shown to reduce myocilin production in human trabecular meshwork cell culture systems. $^{35}$

No adverse effects of synthetic thyroxine on the human eye have been reported in pharmacology literature. ${ }^{27,37}$ In frogs, the normal development of the ipsilateral retinothalamic projections ${ }^{38}$ is inhibited by propylthiouracil and restored by the intraocular injection of thyroxine. ${ }^{39}$ It is uncertain if thyroxine exerts morphogenetic effects on the mature central nervous system of other species, or if effects at later stages of development are limited to regulation of metabolism. ${ }^{38}$

As there is a strong immunological basis for both hypothyroid and hyperthyroid conditions, the borderline association found between glaucoma and any reported thyroid disease could suggest an autoimmune mechanism in glaucoma development. Autoimmunity may also be linked with glaucoma pathogenesis. ${ }^{40,41}$ One report identified a possible association between normal tension glaucoma and immunoreactive tendencies ${ }^{41}$ and speculated that an autoimmune response to a sensitizing 
antigen may inflict damage to retinal ganglion cells or to the optic nerve vasculature. ${ }^{40,41}$ Autoimmune-mediated glaucoma injury may be more frequent in subjects in whom IOP has never been found to be elevated ${ }^{40,41}$ and could represent an autoimmune neuropathy.

Monoclonal paraproteins, autoantibodies to heat-shock proteins and glycosaminoglycan antibodies have been found in subjects with normal tension glaucoma. ${ }^{40}$ These findings may be relevant in light of the association found between thyroid disease and LPG in our study. Although we have no serum antibody titres to directly support the autoimmune theory, the borderline association found between history of thyroid disease (regardless of thyroid activity) and OAG provides tentative support for this notion. Further experimental studies to unravel the role of autoimmunity in glaucoma would be of interest.

The increased odds for OAG found in subjects with history of hyperthyroidism or $\mathrm{I}^{131}$ treatment could relate to well-documented thyroid-associated orbitopathy. Proposed causes of glaucoma in hyperthyroid subjects include extraocular muscle contraction against orbital adhesions, ${ }^{10}$ trabecular meshwork mucopolysaccharide deposition, direct thyrotoxic effects, a genetically linked predisposition, ${ }^{4,12}$ optic nerve head ischaemia or decreased resistance to IOP. ${ }^{42}$ Thyroid-associated orbitopathy in Graves' disease can increase IOP by blocking episcleral aqueous outflow. ${ }^{10}$

In the absence of compressive optic neuropathy, relationships between OAG and ocular hypertension due to Graves disease ${ }^{10}$ or hyperthyroidism ${ }^{43}$ have been documented, particularly when active thyroid-associated orbitopathy is long-standing. ${ }^{4}$ This could lead to sustained IOP elevation in hyperthyroid subjects, with subsequent development of OAG.

In conclusion, our findings suggest the possibility of an association between glaucoma and thyroid disease, particularly in subjects currently treated with thyroxine. Further evaluation of this potential association is warranted.

\section{References}

1 Guyton AC, Hall JE. Textbook of Medical Physiology, 9th ed. Saunders: Philadelphia, 1996; pp 945-956.

2 Braunwald E, Fauci AS, Kasper DL Harrison's Principles of Internal Medicine, 15th ed. McGraw-Hill: New York, 2001; pp 2066-2069.

3 Toft AD. Thyroxine therapy. N Engl J Med 1994; 331: 174-180.

4 Cockerham KP, Pal C, Jani B, Wolter A, Kennerdell JS. The prevalence and implications of ocular hypertension and glaucoma in thyroid-associated orbitopathy. Ophthalmology 1997; 104: 914-917.

5 Smith KD, Arthurs BP, Saheb N. An association between hypothyroidism and primary open-angle glaucoma. Ophthalmology 1993; 100: 1580-1584.
6 McLenachan J, Davies DM. Glaucoma and the thyroid. $\mathrm{Br}$ J Ophthalmol 1965; 49: 441-444.

7 Smith KD, Tevaarwerk GJ, Allen LH. An ocular dynamic study supporting the hypothesis that hypothyroidism is a treatable cause of secondary open-angle glaucoma. Can J Ophthalmol 1992; 27: 341-344.

8 Smith KD, Tevaarwerk GJ, Allen LH. Reversal of poorly controlled glaucoma on diagnosis and treatment of hypothyroidism. Can J Ophthalmol 1992; 27: 345-347.

9 Boles CB, Mignone U, Vadala G, Gastaldi C, Favero C, Brogliatti B. Glaucoma and hypothyroidism. Acta Ophthalmol Scand Suppl 1997; 224: 47-48.

10 Ohtsuka K, Nakamura Y. Open-angle glaucoma associated with Graves disease. Am J Ophthalmol 2000; 129: 613-617.

11 Gillow JT, Shah P, O'Neill EC. Primary open angle glaucoma and hypothyroidism: chance or true association? Eye 1997; 11: 113-114

12 Cheng $\mathrm{H}$, Perkins ES. Thyroid disease and glaucoma. $\mathrm{Br} \mathrm{J}$ Ophthalmol 1967; 51: 547-553.

13 Karadimas P, Bouzas EA, Topouzis F, Koutras DA, Mastorakos G. Hypothyroidism and glaucoma. A study of 100 hypothyroid patients. Am J Ophthalmol 2001; 131: $126-128$.

14 Munoz-Negrete FJ, Rebolleda G, Almodovar F, Diaz B, Varela C. Hypothyroidism and primary open-angle glaucoma. Ophthalmologica 2000; 214: 347-349.

15 McDaniel D, Besada E. Hypothyroidism - a possible etiology of open-angle glaucoma. J Am Optom Assoc 1996; 67: 109-114.

16 Mitchell P, Smith W, Attebo K, Wang JJ. Prevalence of agerelated maculopathy in Australia. The Blue Mountains Eye Study. Ophthalmology 1995; 102: 1450-1460.

17 Mitchell P, Smith W, Attebo K, Healey PR. Prevalence of open-angle glaucoma in Australia. The Blue Mountains Eye Study. Ophthalmology 1996; 103: 1661-1669.

18 Australian Bureau of Statistics. CData91: Australian Population Census 1991. Cat. No. 2721.0-8. 1994. Canberra.

19 Klein BE, Magli YL, Richie KA, Moss SE, Meuer SM, Klein R. Quantitation of optic disc cupping. Ophthalmology 1985; 92: 1654-1656.

20 Working Party of the Australian Diabetes Society. Revised criteria for diagnosis of diabetes. Med J Aust 1993; 158: 566-567.

21 Sawin CT, Castelli WP, Hershman JM, McNamara P, Bacharach $\mathrm{P}$. The aging thyroid. Thyroid deficiency in the Framingham Study. Arch Intern Med 1985; 145: 1386-1388.

22 Sawin CT, Geller A, Hershman JM, Castelli W, Bacharach P. The aging thyroid. The use of thyroid hormone in older persons. JAMA 1989; 261: 2653-2655.

23 Parle JV, Franklyn JA, Cross KW, Jones SC, Sheppard MC. Prevalence and follow-up of abnormal thyrotrophin (TSH) concentrations in the elderly in the United Kingdom. Clin Endocrinol (Oxf) 1991; 34: 77-83.

24 Bemben DA, Winn P, Hamm RM, Morgan L, Davis A, Barton E. Thyroid disease in the elderly. Pt 1 . Prevalence of undiagnosed hypothyroidism. J Fam Pract 1994; 38: 577-582.

25 Canaris GJ, Manowitz NR, Mayor G, Ridgway EC. The Colorado thyroid disease prevalence study. Arch Intern Med 2000; 160: 526-534.

26 Brochmann H, Bjoro T, Gaarder PI, Hanson F, Frey HM. Prevalence of thyroid dysfunction in elderly subjects. A randomized study in a Norwegian rural community. Acta Endocrinol (Copenhagen) 1988; 117: 7-12. 
27 Bochner F, Hill R, Nation R et al. Australian Medicines Handbook. Australian Medicines Handbook Pty Ltd, 2002, pp 346-350.

28 Cooper DS. Thyroid hormone treatment: new insights into an old therapy. JAMA 1989; 261: 2694-2695.

29 Duncan KG, Jumper MD, Ribeiro RC, Bailey KR, Yen PM, Sugawara A et al. Human trabecular meshwork cells as a thyroid hormone target tissue: presence of functional thyroid hormone receptors. Graefes Arch Clin Exp Ophthalmol 1999; 237: 231-240.

30 Knepper PA, Covici S, Fadel JR, Chandra SKM, Ritch R. Surface-tension properties of hyaluronic acid. J Glaucoma 1995; 4: 194-199.

31 Stone EM, Fingert JH, Alward WLM, Nguyen TD, Polansky JR, Sunden SLF et al. Identification of a gene that causes primary open angle glaucoma. Science 1997; 275: 668-670.

32 Alward WL, Fingert JH, Coote MA, Johnson AT, Lerner SF Junqua D et al. Clinical features associated with mutations in the chromosome 1 open-angle glaucoma gene (GLC1A). N Engl J Med 1998; 338: 1022-1027.

33 Fautsch MP, Bahler CK, Jewison DJ, Johnson DH. Recombinant TIGR/MYOC increases outflow resistance in the human anterior segment. Invest Ophthalmol Vis Sci 2000; 41: 4163-4168.

34 Ricard CS, Agapova OA, Salvador-Silva M, Kaufman PL, Hernandez MR. Expression of myocilin/TIGR in normal and glaucomatous primate optic nerves. Exp Eye Res 2001; 73: 433-447.
35 Polansky JR, Fauss DJ, Zimmerman CC. Regulation of TIGR/MYOC gene expression in human trabecular meshwork cells. Eye 2000; 14(Part 3b): 503-514.

36 Tamm ER, Russell P, Epstein DL, Johnson DH, Piatigorsky J. Modulation of myocilin/TIGR expression in human trabecular meshwork. Invest Ophthalmol Vis Sci 1999; 40: 2577-2582.

37 Carroll PR, Carter WJ, Flecknoe-Brown S et al. 2000 MIMS Annual. Tien Wah Press Ltd: Australia, 2000, pp 527-530.

38 Hofmann $\mathrm{MH}$, Michler A, Meyer DL. Thyroxine influences neuronal connectivity in the adult frog brain. Brain Res 1989; 492: 389-391.

39 Hoskins SG, Grobstein P. Development of the ipsilateral retinothalamic projection in the frog Xenopus laevis. III. The role of thyroxine. J Neurosci 1985; 5: 930-940.

40 Wax MB. Is there a role for the immune system in glaucomatous optic neuropathy? Curr Opin Ophthalmol 2000; 11: 145-150.

41 Cartwright MJ, Grajewski AL, Friedberg ML, Anderson DR, Richards DW. Immune-related disease and normal-tension glaucoma. A case-control study. Arch Ophthalmol 1992; 110: 500-502.

42 Hayreh SS, Zimmerman MB, Podhajsky P, Alward WL. Nocturnal arterial hypotension and its role in optic nerve head and ocular ischemic disorders. Am J Ophthalmol 1994; 117: 603-624.

43 Sarda RP, Mehrotra AS, Adnani R, Sharma RG. A study of glaucoma in relation with thyroid dysfunction. Eye Ear Nose Throat Mon 1972; 51: 183-186. 